\title{
Configurações recentes das favelas cariocas: três cenas da "pacificação".
}

Thiago Oliveira Lima Matiolli;

Rachel Barros de Oliveira;

Daniel Soares Rodrigues

Em 1998, Alba Zaluar e Marcos Alvito decretavam, definitivamente, que "a favela venceu" (Zaluar e Alvito, 2006:21). Qualificando (e, a nosso ver, polemizando contra) esta tese, Machado da Silva pergunta: "mas, e o favelados?" (Machado da Silva, 2002:223). Ele argumenta, convincentemente, que o encapsulamento da ação coletiva favelada foi o preço pago pela conquista, a duras penas, de "permanência, aceitação e reconhecimento institucional e simbólico" (idem, ibidem) para a favela e seus moradores, o que significa dizer que a "vitória" da favela teve como contrapartida a "derrota" dos favelados. Desde 2008, a população do Estado do Rio de Janeiro (sobretudo da capital) assiste à implementação do que se convencionou designar como uma inovadora política de segurança: as Unidades de Polícia Pacificadora (doravante, UPPs). Gozando (ainda hoje, apesar dos pesares) de grande prestígio (senão como ato, ao menos como ideia), pode-se dizer que as UPPs venceram; mas, e os "pacificados"?

Com o intuito de reagir a esta (auto-)provocação, o artigo, propondo uma leitura das favelas cariocas enquanto margens urbanas do Estado (a partir da já clássica perspectiva teórica avançada por Das e Poole, 2004), analisa três cenas (ou episódios) ocorridos em áreas oficialmente "pacificadas" e que têm na atuação policial seu centro gravitacional. O intuito é o de mostrar, à semelhança do argumento de Machado da Silva, que a vitória das UPPs vem se dando à custa da manutenção de favelas e favelados como (ou nas) margens do Estado. 
O termo "pacificação" (e algumas de suas variantes, como "pacificado") vai sempre entre aspas em função da enorme polivalência que advém dos usos e desusos a que é submetido pelos diferentes agentes em suas disputas definicionais (ontem e hoje). Vale destacar, no entanto, que o termo tem tradição não apenas nas ciências sociais (como, por exemplo, Elias, 1994, 1994a; Wouters, 1999; Wermelinger, 2012, dentre muitos outros), mas, sobretudo, dentre as "tecnologias do governamental" (Chaterjee, 2012: 110) do Estado brasileiro, com foco na questão indígena (como podemos ver em Pacheco de Oliveira, 2014 e Lima, 1995), mas não apenas, como se pode ver nas crônicas jornalísticas de 1926 e 1936 publicadas no Correio da Manhã e na Revista da Semana, trechos das quais se encontram em Gonçalves (2013: 78 e 111), nas quais a favela é construída retoricamente como território necessitado de "pacificação" pelas "forças da ordem"1 $^{1}$. O devido tratamento sociológico desta questão (que não é somente terminológica) transborda os limites deste artigo, o uso das aspas servindo de

\footnotetext{
${ }^{1}$ Quer dizer, embora enraizado numa conjuntura histórica muito particular e original, o projeto de "pacificação" de favelas guarda ressonâncias históricas não apenas com o indigenismo nacional, mas também com a própria história social do fenômeno das favelas cariocas. Os trechos a seguir destacados das crônicas acima referidas dão o tom do que pretendemos ressaltar: 1) Em 19 de maio de 1926, o Correio da Manhãa, a respeito dos diferentes arranjos que tiveram de ocorrer entre as autoridades oficiais e os "chefes locais" (numa antecipação dos atuais "donos de morro" - Grillo, 2013) do (então) Morro da Favella por ocasião da visita do poeta futurista Filippo Tommaso Marinetti, escrevia: "A situação evoluiu. As autoridades portaram-se à altura dos acontecimentos. A polícia não podia permanecer em pelotões no morro. Veio uma perfeita situação de entente-cordiale com os mais prestigiosos dungas. As autoridades da zona tacitamente delegavam poderes a esses obedecidos, homens fortes que passaram officiosamente a agir como representantes do commissário [de polícia]. Só assim se resolveu o problema da pacificação da favella" (In: Gonçalves, 2013:78 - grifo nosso); e 2) Em 15 de agosto de 1936, a Revista da Semana publicava crônica intitulada "A Favella Regenerada", assinada por João Licino de Miranda e na qual lemos, a respeito de um abaixo-assinado organizado pelos moradores do "morro da Mangueira" solicitando ao "chefe de Polícia do Districto Federal (...) a creação de um posto policial" nos limites da "lendaria Favella da Mangueira", a seguinte exortação (no último parágrafo): "Sr. Chefe de Polícia do Distrito federal: attendei, pois, a essa gente! A Favella quer viver em paz, fazer parte do nosso meio, respeitando ou discutindo conosco as nossas leis, tomando parte nos festejos solemnes das nossas datas históricas, entrando em nossos salões e admirando as nossas artes e os nossos hábitos de povo civilisado! A Favella está pacificada, regenerada! Todavia, Sr. Chefe da Segurança do Districto, creado o posto policial no cocoruto do morro, enviae para ali, por cautela, homens fortes e decididos: o tigre, depois de ferido e moribundo, ainda mata três caes de uma dentada" (a crônica completa encontra-se em http://memoria.bn.br/DocReader/DocReader.aspx?bib=025909_03\&PagFis=16199\&Pesq=; último acesso em $11 / 08 / 2015)$.
} 
desnaturalização da categoria e, portanto, de lembrança das profundas implicações (empíricas e teóricas) aí presentes.

Este artigo é o resultado da confluência de etnografias e interesses de pesquisa de três pesquisadores/as situados/as em diferentes lugares da cidade e em diferentes momentos da construção de suas teses de doutorado em sociologia, o que the confere uma natureza assumidamente ensaística, espécie de sobrevoo de natureza exploratória. O panorama apresentado pelas três cenas que servem de referencial empírico do artigo, embora limite seus alcances generalizantes, confere fôlego e sustentação à perspectiva teórica adotada, cujas possibilidades e problemas de pesquisa não podem, contudo, ser aqui esgotados.

O artigo divide-se em cinco seções. Na sequência desta introdução, realizamos um breve apanhado sobre a história das favelas cariocas e sobre o discurso oficial relativo às UPPs, destacando, uma vez mais, o mote da inquietação que inspira o artigo. Na terceira seção, depois de apresentarmos (sucintamente) as três áreas em que realizamos nossas pesquisas, descrevemos as cenas nelas ocorridas e que servem de esteio para o argumento geral do artigo. Na quarta seção, desenvolvemos a orientação teórica do trabalho, destacando que a perspectiva das margens do Estado voltadas para o entendimento da realidade das favelas cariocas não reproduz equívocos de outras abordagens de pesquisa, constituindo-se, nesse movimento, como alternativa extremamente profícua e original para o avanço sociológico naquele entendimento. $\mathrm{Na}$ quinta e última seção, resumimos o sentido e o fio condutor do artigo, enfatizando, novamente, os horizontes de pesquisa que lhes são inerentes. 


\section{A vitória das favelas e a vitória das UPPs.}

A vitória das favelas, isto é, a sua conquista de permanência geográfica e reconhecimento institucional e simbólico, explica Machado da Silva (2002), assumiu dois arranjos distintos que se imiscuíram de maneira complexa ao longo da história da cidade do Rio de Janeiro e de acordo com os termos das diferentes conjunturas particulares: tratou-se, de um lado, de uma mescla de tentativas oficiais de remoção e erradicação do fenômeno da favela (tanto na lei quanto na prática) com uma tolerância (ou um reconhecimento) institucional que - todavia - não permitia sua consolidação (também prática e jurídica, como frisa Gonçalves, 2013) e, de outro, da instauração de uma sociabilidade entre poder público (em sentido amplo) e moradores de favela que (deslegitimando a opção remocionista) configurou o que Machado da Silva (idem) chamou de controle negociado, arranjo que permanece até hoje.

Neste sentido, Machado da Silva indica que o Estado desiste da opção remocionista e, negociando apoio político em troca de pequenas obras de urbanização (o que significa o fim - ou o significativo arrefecimento - de estratégias combativas de organização política por parte dos favelados), renova seu lugar de agente de manutenção do fenômeno da favela. Do ponto de vista dos favelados, esse arranjo é positivo por manter (fisicamente) a favela e afastar o fantasma da remoção, mas é exatamente este fantasma que está sempre pairando por detrás das investidas do poder público que configuram aquela negociação, o que significa que a interlocução é extremamente desigual. Assim, "as remoções não desaparecem completamente: é como se a alternativa hibernasse" (idem: 231). E a alternativa tanto hibernou (Machado da Silva falava, aqui, sobretudo, da década de 1950) que deslanchou entre 1968 e 1975, novamente declinou (a ponto de a favela ser decretada "vencedora") e atualmente 
retornou (ainda que requalificada/reatualizada) no contexto dos mega-eventos da cidade (cf. Gonçalves et alii, 2013b; La Barre, 2013; Brum, 2013). Evidentemente, tudo isto nos leva a no mínimo desconfiar da ideia de que a favela venceu, já que, porque nas margens, seus moradores precisam recriar cotidianamente esta vitória, que nunca está plenamente garantida (porque sobre o pano de fundo da insegurança e da instabilidade jurídicas também permanentemente recriadas).

Naquele contexto de uma "reatualização das práticas e discursos da remoção" (Magalhães, 2013:75²), em que já se configurou na cidade (e no país) um repertório prático-cognitivo que Machado da Silva (1993, 1994, 2008, dentre outros) vem chamando de linguagem da violência urbana e uma ordem social por ele designada de sociabilidade violenta, o experimento das UPPs deslancha (na opinião pública e nos documentos oficiais) como carro-chefe de um novo e virtuoso processo integração da cidade, o que envolveria (finalmente) a absorção da cidade informal pelas instituições da cidade formal e que incluiria desde a expansão (qualitativa e quantitativa) de serviços públicos até o fortalecimento de práticas empreendedoras, passando pelo favorecimento do surgimento de novas lideranças comunitárias.

\footnotetext{
${ }^{2}$ No início de sua tese, Alexandre (Magalhães, 2013:12) nos lembra de uma entrevista que o prefeito Eduardo Paes (hoje no seu segundo mandato) concedeu à revista Veja logo após tomar posse de seu primeiro mandato (em 2009), dizendo que "estigmatizar a remoção é uma irresponsabilidade". Parte da entrevista pode ser lida em http://planetasustentavel.abril.com.br/noticia/desenvolvimento/conteudo_471538.shtml?func=2 (último acesso em 11/08/2015). Exemplar, neste contexto, é a seguinte passagem do prefeito: "ali [no subúrbio], a lógica do processo está invertida: áreas degradadas, como as favelas, vão ocupando e destruindo o tecido urbano consolidado. Meu sonho como prefeito é inverter esse fluxo, investir nos bairros e fazer com que a lógica da cidade formal passe a influenciar as áreas onde a favela avançou, possibilitando que haja um adensamento populacional civilizado". Igualmente representativa da atualização do léxico remocionista é a série de artigos publicadas n'O Globo em 2005 (em perfeita consonância com as "batalhas" ou "cruzadas morais" contra as favelas cariocas lideradas, em outros momentos da cidade, por Augusto Pimenta e Carlos Lacerda), intitulada "Ilegal, e daí" e analisada por Gonçalves (2013:341-350). Para uma análise crítica das remoções atualmente, cf. Remoções no Rio de Janeiro Olímpico (2015). Nele, Faulhaber e Neves mostram, por exemplo, que a gestão Eduardo Paes removeu 67 mil pessoas, ao passo que as gestões de Carlos Lacerda e Pereira Passos, juntas, removeram 50 mil cidadãos.
} 
Como sublinha Leite (2014:626; grifos da autora), o "programa estadual de pacificação de favelas (...) foi sendo criado ad hoc"; quer dizer, não obedeceu a um plano pré-definido e previamente desenhado, mas avançou de maneira pragmática e experimental, com baixo grau de institucionalização e normatização legal. Basta ver que o decreto 42.787 de 06 de janeiro de 2011, único a avançar mais concretamente na determinação jurídica do modus operandi das UPPs, foi primulgado quando o "projeto de pacificação" já somava 13 (treze) unidades, sendo a primeira inagurada em 19 de dezembro de 2008 - hoje, como se sabe, há 38 UPPs no Estado do Rio de Janeiro (estando apenas uma fora de sua capital). Por esse motivo, referimo-nos às UPPs como um "experimento" e não como uma política pública (seguindo a sugestão de Rodrigues e Siqueira, 2012:13).

$\mathrm{O}$ mesmo decreto, em seu inciso III, art. $2^{\underline{0}}$, pode ser tomado como exemplar daquela construção da UPPs como o agente de um processo de integração da cidade; lá, lemos que as UPPs têm em seus horizontes a "reintegração da comunidade à sociedade democrática". O $\S 2^{\underline{0}}$ do art. $1^{\underline{0}}$ deste mesmo decreto ainda estabelece como sendo os objetivos das UPPs: a) "consolidar o controle estatal sobre comunidades sob forte influência da criminalidade ostensivamente armada"; e b) "devolver à população local a paz e a tranquilidade públicas necessárias ao exercício da cidadania plena que garanta o desenvolvimento tanto social quanto econômico"3. O sítio eletrônico oficial das UPPs afirma, ainda, que as UPPs foram elaboradas "com os princípios da polícia de proximidade, um conceito que vai além da polícia comunitária e tem sua estratégia fundamentada na parceria entre a população e as instituições da área de Segurança Pública". Lê-se, lá, que "a atuação da polícia pacificadora, pautada pelo diálogo e pelo

${ }^{3} \mathrm{O}$ decreto $\mathrm{n}^{\circ}$ 44.177/13 adiciona, como sendo um dos objetivos das UPPs, a seguinte alínea: “c) aplicar instrumentos mais céleres, eficazes e plurais à resolução e ao encaminhamento de ocorrências, com ênfase na mediação e na destinação de tratamento diferenciado aos delitos de pequena monta." 
respeito à cultura e às características de cada comunidade, aumenta a interlocução e favorece o surgimento de lideranças comunitárias" e que "a pacificação ainda tem um papel fundamental no desenvolvimento social e econômico das comunidades, pois potencializa a entrada de serviços públicos, infraestrutura, projetos sociais, esportivos e culturais, investimentos privados e oportunidades."4

Sinal do sucesso político das UPPs (a despeito de todos os fatos retumbantes envolvendo a rotineira violação de direitos humanos por parte das forças policiais em territórios "pacificados"5 e apesar de visível esfriamento do furor otimista inicial envolvendo a experiência da "pacificação") foi a última disputa eleitoral pelo governo do Estado do Rio de Janeiro (ocorrida em 2014), em que nenhum dos principais candidatos propôs o fim ou a reformulação radical da experiência de policiamento inaugurada em 2008. Luiz Fernando Pezão (eleito no segundo turno e candidato pelo PMDB), Anthony Garotinho (do PR), Marcelo Crivella (do PRB) e Lindbergh Farias (do

\footnotetext{
${ }^{4}$ Disponível em: http://www.upprj.com/index.php/faq (último acesso em 23/02/2015). Num vídeo institucional que o site das UPPs exibia até fins de 2013, mas hoje indisponível, o secretário de segurança pública do Estado, José Mariano Beltrame, afirmava: "para as UPPs, nós fizemos um diagnóstico mais ou menos de dezesseis a dezoito meses do Rio de Janeiro e se percebe nitidamente uma cidade partida. Você tem pontos aonde o Estado não está (...) O que vai resolver o problema da segurança pública é o atendimento de demandas sociais, quanto mais demanda social atendida eu tiver, menos polícia eu vou precisar (...) O que nós estamos fazendo aqui nada mais é... é buscar, permitir atender as pessoas que estão aqui [na favela] como as que estão lá embaixo [fora da favela]. Que antes existia um discurso cínico do Estado dizendo: 'eu não posso botar uma professora lá no Vidigal porque o tráfico não deixa, eu não posso botar uma creche porque o tráfico não deixa, eu vou ter que pedir licença'; então, agora, isso não existe mais, então agora faça. As pessoas precisam entender que a UPP é o elo de uma corrente. Outras coisas tem que ser feitas. Nós não podemos espalhar as UPPs pela cidade e achar que o problema de segurança pública está resolvido."

${ }^{5}$ As fontes, a esse respeito, são inúmeras. Uma amostra pode ser encontrada no Megaeventos e Violações de Direitos Humanos no Rio de Janeiro: Dossiê do Comitê Popular da Copa e Olimpiadas do Rio de Janeiro (2014), nas denúncias de diversos movimento sociais (como no caso da Marcha contra o Genocídio do Povo Negro e da Rede de Comunidades e Movimentos contra a Violencia) e no caso, mais recente e amplamente divulgado pela mídia, do menino Eduardo de Jesus, de 10 anos, brutalmente assassinado no Complexo do Alemão pelo Batalhão de Choque da Polícia Militar; sobre este caso, ver, dentre muitas: http://odia.ig.com.br/noticia/rio-de-janeiro/2015-0809/justica-aqui-so-vale-para-preto-e-pobre-diz-mae-de-menino-morto-no-alemao.html (último acesso em 11/08/2015). Por outro lado, dados recentes do ISP (Instituto de Segurança Pública) e de pesquisa coletiva presente em CANO et alii (2012), afirmam que as taxas de homicídio em áreas de UPP caíram consideravelmente; sobre os dados do ISP, ver http://oglobo.globo.com/rio/numero-de-homicidios-por-intervencao-policial-em-areas-com-uppcai-853-em-sete-anos-16122782 (último acesso em 11/08/2015).
}

$3^{\text {RASILIANA- Journal for Brazilian Studies. Vol. 4, n.2 (2016). ISSN 2245-4373. }}$ 
PT) somaram, no primeiro turno, 90,3\% dos votos válidos e todos, sem exceção, apoiaram publicamente (durante as campanhas) o projeto das UPPs, embora não sem algumas sugestões de aperfeiçoamento ${ }^{6}$. Esse dado nos aponta para certa hegemonia discursiva que o projeto das UPPs ocupa na opinião pública, o que se reflete, inclusive, em determinados estudos urbanos que colocam a experiência da "pacificação" em íntima relação com o desenvolvimento econômico das favelas da cidade - o que se vê, por exemplo, no entendimento das favelas na chave da "oportunidade" (Pastuki et alii, 2012) ou, dito de outro modo, enquanto constituindo um "formidável laboratório da nova economia popular" (Meirelles e Athayde, 2014). Nesses enquadramentos, o experimento das UPPs surge como momento privilegiado para a formulação de estratégias e políticas (públicas e/ou privadas) voltadas para o aprofundamento de uma lógica mercantil que o extrapola. De acordo com estas perspectivas, as favelas serão "incluídas" através do "desenvolvimento local" operado a partir - sobretudo - da "promoção da prática do empreendedorismo" (cf. Pastuki et alii, 2012; cf. La Rocque, 2013; cf. La Rocque e Boavista, 2012), o que é facilitado enormemente pelo término, proporcionado pelas UPPs, de uma "vida atormentada pela guerra" (cf. Meirelles e Athayde, 2014:58). É neste sentido, portanto, que afirmamos, na seção anterior, que "as UPPs venceram", questionando-nos sobre o que isto significa para a vida prática dos moradores das favelas convertidas em objeto desta que se pretende uma política de segurança pública inovadora e comunitária.

\footnotetext{
${ }^{6}$ Quanto a isso, dentre várias, cf. http://veja.abril.com.br/noticia/brasil/o-que-pensam-os-candidatos-ao-governo-dorj-sobre/ (último acesso em 11/08/2015). Tarcísio Motta, candidato pelo PSOL e quinto colocado no primeiro turno (com $8,9 \%$ dos votos válidos), foi o único (com uma votação relativamente expressiva) a fazer críticas contundentes às UPPs, propondo, inclusive, a "desmilitarização do Estado", embora defendendo o "policiamento comunitário"; quanto a isso, cf., dentre várias, http://www.brasil247.com/pt/247/favela247/155621/Tarc\%C3\%ADsio-Motta$\%$ E2\%80\%9CA-UPP-n\%C3\%A3o-\%C3\%A9-um-projeto-de-policiamento-comunit $\% \mathrm{C} 3 \% \mathrm{~A} 1$ rio\%E2\%80\%9D.htm (último acesso em 11/08/2015).
} 


\section{Três cenas da "pacificação"}

Os trabalhos de campo a partir dos quais extraímos as cenas a seguir descritas e analisadas foram realizados em três diferentes complexos ${ }^{7}$ de favelas situados na zona norte da cidade do Rio de Janeiro 8 . De acordo com informações encontradas no próprio site oficial das UPPs e no órgão de produção de dados do IPP (Instituto Municipal de Urbanismo Pereira Passos), da PCRJ (Prefeitura da Cidade do Rio de Janeiro), o SABREN (Sistema de Assentamentos de Baixa Renda)', aqueles três complexos, juntos, abrigam cerca de 70 mil moradores.

A cena 1 desenrola-se numa área de favela abarcada por uma UPP inaugurada no início de 2013, a qual, de acordo com informações oficiais, "beneficia" quase 40 mil habitantes distribuídos por cerca de 10 diferentes favelas. A cena 2, por sua, se passa em uma favela convertida em objeto do experimento das UPPs no início de 2011; a UPP responsável pelo perímetro do qual ela faz parte "atende", segundo os dados oficiais, cerca de 20 mil pessoas distribuídas em 7 diferentes áreas de favela. A cena 3, por fim, ocorre numa localidade cuja UPP foi inaugurada no primeiro semestre de 2012; segundo

\footnotetext{
7 Ao contrário do que apontam Alvito (2002) e Machado da Silva (2010), a ideia de complexo de favelas não foi produzida pela polícia para subsidiar certa lógica de atuação em algumas favelas. O primeiro chega a dizer que ela é oriunda da ideia de "complexo penitenciário". A noção começa a ser utilizada nos estudos sobre favelas realizadas pela prefeitura do Rio de Janeiro, sobretudo pelo antigo IPLANRIO, na década de 1980, de modo a reconhecer a homogeneidade geográfica entre favelas contíguas umas às outras, mas também a heterogeneidade histórica e política de cada uma delas. Foi amplamente utilizada na construção da classificação de favelas que serviu de base para a seleção das favelas que receberiam, ou não, as obras do Favela-Bairro. Se houve uma apropriação de seus sentidos pelo aparato policial, isso é outra história, ainda por ser contada (Matiolli, 2016).

8 A fim de preservar as identidades de nossos interlocutores, todos os nomes (de pessoas e lugares) são fictícios. Na esteira da proposta ensaística e panorâmica do artigo e fiel à ideia de preservação das identidades, esta seção apresenta dados e informações dos locais em que realizamos nossas pesquisas de maneira deliberadamente genérica e superficial.

9 É o SABREN que define oficialmente determinadas áreas da cidade como sendo "de favela"; essa classificação, vale destacar, é a mesma que informa a definição dos perímetros oficiais de abrangência das diferentes UPPs do Estado.
} 
dados locais, esta UPP abrange 5 distintas áreas de favela, que abrigam mais de 10 mil moradores.

As cenas aqui descritas se prestam a um exercício analítico inspirado, para além da alternativa teórica avançada por Das e Poole, pela perspectiva de uma "etnografia experimental", tal como proposta por Vera Telles (2010), o que significa dizer que os dados de campo assumem um protagonismo impossível em abordagens, das quais nos distanciamos, que se utilizam da empiria apenas para reforçar esquemas teóricos cuja validade já está presumida. Deste modo, embora seja um truísmo dizer que esquemas teóricos informam a forma e o conteúdo dos dados empíricos acessados (e, assim, construídos), e não fugimos de explicitar a partir de qual agenda política e analítica nós partimos, permanecemos atentos para não cometer o erro da mera reificação de conceitos previamente constituídos ${ }^{10}$. Tal como argumentamos na próxima seção, se usamos a perspectiva das margens do Estado para analisar as cenas descritas, é por entendermos que esta alternativa teórica não reproduz equívocos de outras perspectivas no campo dos estudos urbanos, como, por exemplo, o de que as margens do Estado são definidas por uma atuação falha ou insuficiente dos seus aparelhos e agências.

As cenas a seguir também não são, e não foram escolhidas por serem, exemplos e casos interessantes, mas porque sua análise conjunta compõe uma cartografia política a partir da qual é possível traçar e propor novas questões e interpretações, sempre parciais e abertas. Nas palavras da autora:

não se trata de partir de objetos ou entidades sociais tais como se convencionou definir de acordo com os protocolos científicos da ciências

10 Sobre esse problema, especificamente epistemológico, ver Barbosa e Renoldi (2013), especificamente quando dizem: "sobre os vícios conceituais, existe aqui a preocupação em desenvolver pesquisas etnográficas por resistência ou oposição às abordagens analíticas que se sustentam sobre noções constituídas a priori" (idem:12). 
sociais (o trabalho, a família, a moradia), mas, sim, de situações e configurações sociais a serem tomadas como 'cenas descritivas', que permitam seguir o traçado dessa constelação de processos e práticas, suas mediações e conexões" (Telles, 2010: 25).

As cenas a seguir são interessantes (e se tornaram pertinentes dado o recorte geral do trabalho) por serem situações a partir das quais nos parece possível etnografar o Estado no exato momento em que ele reinventa suas formas de governar nas margens que ele próprio produz.

\section{Cena 1}

A primeira cena que iremos apresentar será recontada a partir dos relatos feitos por alguns moradores ${ }^{11}$. O fato aconteceu em meados de 2014, menos de um ano após a ocupação militar deste complexo de favelas. Num dia de terça-feira, numa das partes da favela mais densamente povoada e historicamente reconhecida como espaço de $\operatorname{conflitos}^{12}$, um morador resolve fazer uma festa de aniversário regada a cerveja, churrasco e música alta, para celebrar o aniversário de dois anos de sua filha. Um outro morador da mesma rua, interpelado por sua sogra sobre o barulho incômodo num dia de semana, vai até a casa do organizador da festa para reclamar e pedir que o volume do

\footnotetext{
${ }^{11}$ As informações apresentam certa imprecisão por se tratar de um fato bastante conhecido pelos moradores da favela e, por esse mesmo motivo, ser passível de receber várias versões.

${ }^{12} \mathrm{O}$ local é próximo de onde ocorram duas mortes causadas por policiais da UPP, bem como é um dos lugares ocupados por traficantes locais de drogas ilícitas.
} 
som diminua. A conversa entre os dois homens vira uma intensa discussão, e o morador que foi fazer a reclamação acaba esfaqueando o homem que organizou a festa.

O morador esfaqueado chega a ser socorrido na unidade de saúde de emergência do entorno, mas não resiste. A ação inusitada do outro morador, causando a morte de alguém da favela numa ocasião festiva, gera enorme comoção na vizinhança. Como retaliação, sua casa foi invadida, além de ter sido alvo de garrafas e pedras. Por sua vez, o morador reponsável pelo crime começa a ter uma atitude de desespero, como nos contou C., "andando de um lado pro outro no terraço, como se estivesse enjaulado", pois sabia que sua ação teria consequências irreversíveis. Em pouco tempo um grupo de homens chega até sua casa - todos sabiam que aqueles eram os homens envolvidos com o tráfico de drogas, e que tinham o poder de decidir sobre a vida e a morte de qualqer um naquele lugar - e o leva, cena presenciada por seu filho de oito anos, familiares e todos os outros moradores que estavam na rua. E num determinado beco, atrás de uma escola municipal, nas proximidades de uma das entradas principais do complexo, o homem foi espancado a pauladas até morrer. Seu corpo sumiu e nunca mais foi encontrado. "Simplesmente levaram, mataram e deram fim. Isso numa comunidade pacificada" reforçou C., ao nos relatar o ocorrido.

A família do homem morto a pauladas ainda procurou pelo seu corpo, sem sucesso. Esposa e sogra se mudaram da favela para o bairro vizinho. Alguns moradores, que também relataram este caso, insistem em dizer que os fatos chegaram até os policiais da Unidade de Polícia Pacificadora do local, e que como respostas os policiais teriam dito que "esse tipo de problema a comunidade mesma resolve"; outros relatam que a família do morador morto a pauladas registrou queixa formal na delegacia, mas que posteriormente foi retirada em virtude de ameaças do tráfico. 
As versões existentes sobre como este fato ocorreu e se desenrolou é o que menos importa. Interessa-nos destacar que, para os diferentes narradores deste caso, a presença policial, enquanto reguladora de conflitos num contexto de violência urbana, se fez ausente. Neste episódio, as leis estabelecidas no âmbito formal da segurança pública não vigoraram e sequer foram acionadas pela instituição policial, como dizem os moradores: “tá ocupado, mas a situação é a mesma de antes. É a lei deles e ninguém se mete". Na fala dos moradores, "deles" corresponde ao poder local do tráfico, que sempre teve suas próprias regras e formas de resolver os conflitos internos das favelas. Com a presença das UPPs e a propaganda do resgate territorial, criou-se a expectativa de que um novo modo de regulação dos conflitos seria estabelecido. Contudo, o que este caso nos mostra é a continuidade de um processo de silenciamento dos moradores, agora legitimado (ou ignorado) tanto por poderes locais, quanto poderes formais, representantes do Estado.

\section{Cena 2}

Inaugurada no primeiro semestre de 2011 na zona norte da cidade, a UPP ZN abrange seis áreas de favela e diz recobrir, sob seu perímetro, cerca de 15 mil habitantes. Em sua sede, policiais, moradores, lideranças locais e gestores públicos (de diferentes ramos administrativos, como SECONSERVA, R.A., RioLuz, COMLURB etc.) se reúnem para discussão de temáticas locais. Marcada pelo seu capitão, a reunião ocorre em julho de 2013 e é a quinta sucessiva (com periodicidade mensal), fazendo parte de uma agenda de Cafés Comunitários que o capitão (que chamaremos de Ronaldo) entende como de fundamental importância para o processo de "pacificação". Para ele, o espaço do Café é um esforço seu (e complementar ao "trabalho estritamente policial", nas suas palavras) na promoção do desenvolvimento local, para o que ele ocuparia o lugar de 
intermediador entre a população e os agentes públicos e privados responsáveis por demandas históricas das favelas da cidade. Naquela reunião de julho, após gestores e lideranças discutirem sobre diversas demandas e aspectos relativos à infra-estrutura urbana e à rede de serviços públicos concernentes àquelas áreas de favela, o capitão faz uma longa fala (de cerca de 45 minutos) sobre o que ele estava considerando ser o ponto de inflexão de um processo iniciado com aquela agenda dos Café Comunitários. Sua fala (que, infelizmente, não poderemos, por falta de espaço, analisar na íntegra) é interessante por evidenciar, por um lado, sua representação acerca do espaço favelado (e seus habitantes) e, por outro, o lugar político que ele atribui a si mesmo ${ }^{13}$, postura esta que dialoga, por sua vez, com a própria auto-imagem das UPPs (propagada publicamente em pronunciamentos e documentos oficiais e, também, por diversos meios de comunicação de massa).

Iniciando aquela fala, o capitão diz que "não se sustenta mais o discurso de que o [diz o nome de uma das favelas] está há anos abandonado"; para ele, "este discurso não cola mais: tava abandonado, mas não tá mais. Tem serviços, mas tem que ter conscientização ${ }^{14 "}$. Coloca-se como tendo fácil e direto acesso ao próprio Secretário de Segurança Pública, a quem não hesita em recorrer para "pressionar os órgãos", mas, repete, "tem que ter conscientização". E, numa fala diplomática e de agradecimento, enfatiza a magnitude do trabalho dos gestores ali presentes.

\footnotetext{
${ }^{13}$ Por falta de espaço, não nos iremos ater às perspectivas dos moradores e lideranças no que tange à gênese e ao desenvolvimento daquele espaço dos Cafés Comunitários, mantendo o foco na perfomance do capitão e no que ela nos diz acerca do experimento das UPPs.

${ }^{14}$ Sobre esse ponto, o capitão complementa, noutro momento, que "as coisas estão acontecendo", mas que se tem que entender o "tempo da máquina. Tá acontecendo, tá chegando, tem que pressionar, mas tem que entender que o tempo da máquina e a burocracia não tem jeito, e tem que ter dever também, tem que olhar pra dentro, e nisso as lideranças tem muito a fazer, muito a ajudar".
} 
Numa comparação com o trabalho policial, arremata que "não tem órgão mais democrático que a polícia: são 24 horas por dia recebendo todo tipo de mazela, de demanda". Ademais, fala que os problemas enfrentados pelas favelas (no que se refere à prestação dos serviços públicos) não seriam tão diferentes assim daqueles presentes na "cidade formal". Neste sentido, diz que havia chegado a hora de olhar pra dentro. Dando uma série de exemplos pessoais, termina dizendo que, morando em um "bairro de classe média alta em Campo Grande" (zona oeste da cidade) e pagando oitocentos reais de IPTU, ficou vários dias sem luz em função de um fio da Light rompido que, segundo ele, "nem por nada era consertado". Avança na ideia de que havia chegado a hora de "olhar pra dentro" e fala que o morador tinha que dar o exemplo para que os gestores escolham [diz o nome da UPP] como alvo de intervenção. Sugeria a necessidade de conquistar os companheiros que lá iam e do fortalecimento das relações interpessoais. Dá o exemplo de que Rodrigo (subcomandante da UPP ZN) trouxe o representante de um órgão público "no aperto de mão... Se a gente conversa, o cara volta".

Sobre este ponto, o capitão utiliza Samuel (o presidente de uma das associações de moradores que fazem parte do perímetro da UPP ZN) como um mau exemplo. Ironizando a maneira e o jeito de Samuel se expressar, o capitão diz que a sua "fachada", sua "performance", seu "desempenho" (para usar termos goffmanianos) espantam os gestores. Diz que sua fala é muito abrupta, truncada e grosseira. Que ao falar, "parece que quer bater". Constrangedoramente e em tom de brincadeira, diz que ele, ao pedir a mulher em casamento, deve ter agido da mesma maneira, dizendo, agressiva e incisivamente, apontando-lhe o dedo: "quer casar comigo? Hein, quer casar?!". Alguns riem e ele fala da necessidade de se tratar bem e reconhecer o trabalho que vem sendo feito, pois as coisas estavam avançando. 
Mais ao fim da reunião, o capitão refere-se a um espaço que estava em processo de desocupação pela $\mathrm{SMH}^{15}$ (mas, antes, dava lugar a um campo de futebol): “ali não vai ser um campo de futebol, mas não vai mesmo!! Eu ponho meu nome nisso, assino meu nome como não vai ser um campo!", exclama o capitão, dedo em riste, justificando que já tinha "campo de futebol demais na comunidade".

\section{Cena 3}

Era março de 2014, uma segunda-feira, mais precisamente. Estava para começar a plenária convocada por um coletivo de jovens de um dos grandes complexos de favelas da cidade do Rio de Janeiro. O início daquele ano havia trazido um recrudescimento da violência policial e um tensionamento desses agentes da segurança pública com as moradoras e moradores de lá, sobretudo negros e jovens, alvos prediletos de incriminação. A atividade se dava ainda no lastro de uma manifestação realizada dias antes contra a prisão de dois rapazes acusados de envolvimento com o comércio ilegal de drogas da área, que sofrera dura repressão por parte da polícia.

O microfone estava aberto para quem quisesse se manifestar e algumas pessoas fizeram uso, jovens ou não, homens e mulheres, que traziam suas opiniões sobre o processo de "pacificação" ou contavam casos, próprios ou de pessoas próximas, que haviam sofrido abuso policial. Histórias que se multiplicaram desde então, tal como as vítimas dos tiroteios que voltariam a ser recorrentes. Ao final da reunião, foi lido um manifesto produzido e assinado por instituições ou coletivos de conjunto de favelas.

A reconstituição desse evento permitiria o desvelamento de um sem número de situações que poderiam ser trabalhadas, sobretudo a partir das falas de cada uma e cada

\footnotetext{
${ }^{15}$ Secretaria Municipal de Habitação.
}

$3^{\text {RASILIANA- Journal for Brazilian Studies. Vol. 4, n.2 (2016). ISSN 2245-4373. }}$ 
um que tomou o microfone. No entanto, vamos nos deter na plateia - o encontro se dava em uma espécie de anfiteatro - e no que se passava em seu entorno durante a plenária. No meio do público, havia um rapaz, jovem ainda no alto de seus quase cinquenta anos, segurando uma folha de caderno onde era possível ler: "Cadê meus R\$200,00". O cartaz fazia referência à matéria do Jornal Extra, de grande circulação na cidade do Rio de Janeiro, na qual se afirmava que a Polícia Civil estaria investigando o pagamento de quantias, que variariam de $R \$ 50,00$ a $R \$ 200,00$, por parte dos "traficantes locais", nos termos do jornal, para que moradoras e moradores participassem de atos de protesto críticos à atuação das Unidades de Polícia Pacificadora da área.

Posteriormente, outra coisa saltou aos olhos e ouvidos, rumores de que as viaturas policiais traziam câmeras nos giroscópios dos veículos e que as pessoas que participavam do evento estariam sendo registradas. Entretanto, para além dos rumores era possível ver policiais com outras câmeras e smartphones na mão filmando deliberadamente a atividade ou ainda com outros dispositivos acoplados em seus coletes. Em contrapartida, alguns participantes da atividade registravam os policiais com seus próprios celulares.

A matéria à qual o cartaz se refere reverbera certo comportamento da opinião pública carioca (que não vem de hoje) em criminalizar de protestos em favelas sempre que alguém é preso ou assassinado em condições pouco claras, ou abertamente arbitrárias, nesses espaços. O que, para além da cena acima e da matéria do jornal, cabe destacar é que o acompanhamento de manifestações contra a ação das Unidades de Polícia Pacificadora e seus agentes nos últimos meses aponta para uma, digamos, captura semântica dos sentidos desses atos na qual a crítica à ação da UPP desemboca diretamente na defesa do assim chamado "tráfico de drogas". Trocando em miúdos, se mobilizar contra esse programa de segurança pública do governo estadual expressaria, 
instantaneamente, a conivência de moradoras e moradores com as atividades ilícitas e a violência do comércio varejista de drogas territorializados nas favelas.

Essa criminalização das expressões políticas faveladas é uma dimensão do processo incriminatório mais amplo no qual todo preso ou morto nesses territórios é sumariamente condenado pela opinião pública. Um exemplo recente disso foi a manifestação do presidente de uma grande ONG carioca sugerindo que uma criança morta por policiais, aos seus 10 anos de idade, seria um "bandido"16; ainda sobre este caso, chegaram a circular pelas redes sociais fotos de outras crianças com armas de fogo na mão, que seriam do menino morto.

\section{Uma análise a partir das margens do Estado.}

A compreensão das cenas descritas acima se torna interessante quando as entendemos desde uma antropologia nas margens do Estado (Das e Poole, 2004). Isto é, de uma perspectiva que se afasta das visões de uma modernidade incompleta do Estado Brasileiro (Telles, 2010), segundo as quais o Estado seria falho ou ausente em determinadas regiões do país. Nas palavras daquelas autoras:

nossa estratégia analítica e descritiva foi nos distanciarmos da imagem consolidada do estado como forma administrativa da organização política racionalizada que tende a desabilitar-se ou desarticular-se ao largo de suas margens territoriais e sociais (Das e Poole, 2004:3).

16 Sobre o caso, cf., dentre várias, http://www.pragmatismopolitico.com.br/2015/04/jose-junior-chama-meninoeduardo-jesus-de-bandido-e-depois-apaga-tudo.html (último acesso em 15/08/2015). 
Neste sentido, se o Estado não se desabilita em suas margens, ou não está ausente, esses são espaços nos quais ele "está constantemente redefinindo seus modos de governar e legislar" (idem, ibidem). As margens não são inertes ou vazias. Em outras palavras, a presença estatal nas suas margens, através de documentos ou dos poderes locais, em vez de estabelecer uma clivagem definitiva entre o legal e o ilegal, abre espaço para uma gama de práticas, tensões e alianças que permitem novas configurações para regulação da ordem. Nas palavras de Das (2004), em artigo do mesmo livro, é nas suas supostas falhas que é possível etnografar o Estado. E é justamente este o ganho teórico que a proposta condensada na ideia de "margens do Estado" nos proporciona; quer dizer, este tipo de análise nos parece particularmente pertinente para a análise do fenômeno das favelas por não reproduzir os equívocos de estudos urbanos que entendem os espaços favelados como resultados de uma atuação falha ou incompleta dos organismos estatais. Ou seja, nestes espaços, o Estado não está nem ausente nem insuficientemente presente, como se tudo pudesse se resumir a reformas administrativas e burocráticas. Pelo contrário, o que, na auto-imagem do Estado como uma máquina racional e burocrática voltada para a gestão de pessoas, territórios e recursos, aparece como espaços e práticas que estão para além de sua atuação positiva (mais precisamente: nas suas margens ou zonas fronteiriças) são, na realidade, produzidos diretamente pela atuação especificamente estatal, são sua condição de possibilidade. Logo, é lá nas supostas falhas e insuficiências do Estado que devemos encontrar seu modo particular de governo.

Sob esta perspectiva, é possível descrever as formas pelas quais o poder é operado diretamente, isto é, em contextos situados, tal como nas cenas acima; e, 
tratando-se de contextos de "pacificação", tecemos agora mais algumas considerações, já sob a ótica das favelas como espaços produzidos como margens pelo Estado ${ }^{17}$.

Por um lado, historicamente, essa produção marginal das favelas toma forma na manutenção de suas precariedade e ilegalidade, as quais sempre foram funcionais do ponto de vista do controle dos favelados. E esse foi um processo (como indica Gonçalves [2013], embora sem retirar desta constatação as consequências teóricas nela implicadas) que "não se desenvolvia à margem da lei, mas, pelo contrário, no próprio cerne do exercício do poder [jurídico]" (Gonçalves, 2013:23). O autor, quando faz esta afirmação, está chamando a atenção para certa tolerância por parte do aparato estatal para com a ilegalidade sob a qual se dava a reprodução das favelas na cidade do Rio de Janeiro, pois, dessa maneira, poderia lhe negar os serviços básicos necessários e criar formas locais de controle desses serviços e dessas populações.

Por outro lado, isso se manifesta também nas práticas de criminalização da pobreza e de sua territorialização nas favelas. Sem nos estender muito nesta análise, impossível de caber nessas páginas, gostaríamos de destacar a configuração mais recente (já desde algumas décadas) desse processo na cidade do Rio de Janeiro, que é marcado pela territorialização do varejo de drogas ilícitas, sobretudo depois da chegada da cocaína (Misse, 2010).

\footnotetext{
17 Interessante notar que, mostrando as (absolutamente necessárias) vantagens e potencialidades que o método etnográfico traz para a análise do Estado (a partir de suas margens enquanto lugar epistemológico), Das e Poole retomam criticamente o processo histórico em função do qual a disciplina antropológica se considerou (desde o início) inapta para tratar do Estado ao mesmo tempo em que este próprio Estado (ou uma imagem específica dele mais precisamente a auto-imagem do Estado europeu como uma máquina burocrática impessoal e racional voltada tanto para a administração de territórios e pessoas quanto para a garantia de direitos constitucionalmente assegurados) constituiu-se, desde o início, como o que Bourdieu chamou de "inconsciente epistemológico do campo [neste caso, do campo do saber antropológico]" (Bourdieu, 2001, p.120). Privilegiando o que Habermas chamou de "mundo da vida", as autoras propõem uma desvinculação epistêmica do Estado enquanto "operador cultural universal" (Das e Poole, 2004, p.05) e uma alternativa teórica para pensá-lo a partir de suas próprias margens. Neste sentido é que é pertinente falar de uma antropologia não apenas das (mas, também nas) margens do Estado.
} 
Misse explica como esse varejo da droga se territorializa nos aglomerados urbanos de baixa renda (favelas, conjuntos habitacionais, loteamentos irregulares...), confundindo-se com eles, num território do tráfico a ser defendido de outras redes de quadrilhas e incursões policiais. $\mathrm{O}$ autor sugere uma diferença entre esse varejo baseado no controle de territórios das formas através das quais se dá o tráfico nas áreas de classe média, de modo que não haveria

uma relação necessária entre drogas ilícitas e montante da violência, a não ser quando o tráfico se territorializa e opera com jovens pobres, submetidos ao sistema da consignação de vendas e à relação de subordinação ao chefe da quadrilha (...) nesse sentido, a sujeição criminal também se 'territorializa', ganha contornos espaciais e amplifica-se nos sujeitos locais e mesmo nas crianças e adolescentes cuja sujeição é esperada" (Misse, 2010:20-21).

Misse parte da análise durkheimiana de que o crime não está no evento ou no autor, mas nas reações ao primeiro e ao segundo, de modo que a acusação, mais do que o crime em si, seria o início do processo de incriminação ${ }^{18}$. No que nos interessa, seguimos a análise de Telles (2010) sobre o trabalho de Misse, quando a autora destaca que esse processo de incriminação abre um feixe de relações que perpassam a experiência urbana, nos quais o uso indiscriminado da violência anda junto com a

\footnotetext{
${ }^{18} \mathrm{O}$ autor faz uma diferenciação entre incriminação e sujeição criminal. Toda sujeição criminal é também incriminação, mas o inverso não ocorre. De modo que a sujeição está ligada a uma espécie de irrecuperabilidade do sujeito do qual se espera que pratique o crime que vai afetar a própria auto-imagem desse sujeito e cuja morte ou desaparecimento podem, inclusive, ser amplamente desejáveis. Esses processos também estão no cerne do que o autor chama de "acumulação social da violência" (Misse, 2006, 2010).
} 
negociação de mercadorias políticas “que variam entre os 'acertos' na partilha dos ganhos, propinas, corrupção, chantagem e extorsão, quer dizer: mercados de proteção, também ilegais, que se sobrepõem às outras ilegalidades e parasitam os mercados informais e ilegais" (Telles, 2010:215).

Sob essa ótica, a ação policial nas favelas e espaços de periferia não se dá num contexto de ausência do Estado, ou no vácuo da lei, pois, como indicam Das e Poole (2004), as margens não são espaços "sem lei", mas regiões de forte presença estatal; ali, o monopólio do Estado é constantemente questionado pelos múltiplos regimes de regulação necessários ao seu funcionamento. Entrementes, essa análise da ação policial foi reconfigurada nas últimas décadas quando, segundo Machado da Silva (2010), se consolidaria outra gramática articuladora do debate público, que ele chama de "linguagem da violência urbana", em detrimento da "linguagem dos direitos".

Nessa linguagem de direitos, a segurança surge como um elemento que trata da questão dos direitos civis e políticos e do controle da ação do Estado na sua função de garantia da ordem e como um repertório legítimo para as demandas populares. É interessante reter aqui que, nessa linguagem, Machado afirma que "a manutenção da ordem pública e o controle das atividades rotineiras" (Machado da Silva, 2010:116) escapam das preocupações da agenda pública e são tidos como derivações dos conflitos estruturais. Com a emergência da linguagem da violência urbana, essas preocupações passam a ocupar o cerne do debate público.

Isso significa, com relação à atividade policial, que esse debate tende a se reduzir ao debate sobre a dimensão repressiva do controle social nas atividades cotidianas. Machado da Silva diz que, mesmo com o processo de democratização iniciado na década de 1980, os aparelhos policiais teriam mantido seu "papel sujo" de controlar e disciplinar as camadas populares. Isso se manifestava nas grandes incursões às favelas, 
que provocavam mortes e aterrorizavam as populações locais. O que contava com apoio tácito de boa parte da população, de modo que não foi possível criar uma "crítica pública organizada capaz de alterar significativamente os repertórios da linguagem da violência urbana" (idem:118).

A partir desta matriz teórica, as cenas descritas nos permitem apontar novos modos pelos quais as formas de governo (e de ação policial, em particular) se reinventam nas favelas "pacificadas" e se somam às negociações sobre as mercadorias políticas, sem anulá-las, gerando novas configurações relativas a sua dimensão repressiva do controle social nas atividades cotidianas.

Na análise de Das e Poole (2004), uma das formas de realização e reconfiguração do Estado nas suas margens é a sua realização através dos poderes e atores locais. O que toma forma em duas das cenas descritas: na figura do capitão da UPP que buscar ser um interlocutor político entre os moradores e as demais agências e serviços públicos, inclusive a partir de suas relações pessoais e de seus subordinados; ou na figura do policial, ou dos policiais, que teriam se negado a registrar a ocorrência ou, não se sabe, fizeram o registro para depois suprimi-lo, sob ameaças.

A (i)legibilidade dos processos de documentações das práticas estatais é uma das formas pelas quais o Estado é reinventado em suas margens. Através desses registros manifesta-se o duplo signo estatal: o distanciamento e sua penetração na vida diária ${ }^{19}$. Ao mesmo tempo em que os moradores das favelas pacificadas convivem diariamente (nas ruas, becos, esquinas, estabelecimentos comerciais...) com policiais, quando é

\footnotetext{
${ }^{19}$ A noção de que o Estado está próximo e distante ao mesmo tempo, é trabalhado por Das (2004) e Das e Poole (2004). O caráter "burocrático", ou racional, do Estado se manifesta nas suas leis e regulamentações; se pensarmos, como estamos argumentando aqui, que essa dimensão legal está distante da produção das favelas como margens, o acesso aos serviços e garantias governamentais está longe ou bloqueado para os moradores desses espaços. Por outro lado, o Estado, através de certos funcionários e agências, se faz presente cotidianamente na vida dessas pessoas, inclusive, representando o aparato estatal em sua totalidade e mesmo reinventado suas regras.
} 
necessário que eles cumpram suas funções regimentais, isso não é feito, tornando o caráter burocrático ainda mais distante; o mesmo acontece quando o capitão da UPP se dispõe a realizar seus cafés comunitários com as lideranças das áreas sob sua jurisdição. Estão próximos também, quando filmam os participantes de uma plenária, tal como trazido na terceira cena.

Essas novas configurações e funções da ação policial em áreas "pacificadas", seu esforço em ser o interlocutor estatal com os moradores em busca de melhorias e serviços ou ainda de se manter distante, em suas premissas básicas de registro de ocorrências, se justapõem à continuidade de práticas mais antigas da polícia nesses espaços. Se já não há, ao menos com tanta frequência, as incursões policiais, a "matabilidade" ${ }^{20}$ dos corpos favelados ainda subsiste, como vemos na cena 1; ou ainda a continuidade do que Machado da Silva chamou, e citamos acima, de crítica pública, a qual sustenta a criminalização desses espaços. O que cria uma armadilha, tal como descrita acima, na qual a crítica às UPPs vinda de pessoas que vivem em áreas faveladas é imediatamente capturada como uma "defesa ao tráfico de drogas", reiterando a territorialização da sujeição criminal de que fala Misse.

Das e Poole (2004) tratam também dessa matabilidade, ressaltando que esses corpos matáveis são produzidos pela própria lei e pelos dispositivos do poder soberano. Não se trata da vida natural, mas da vida produzida como matável. Os policiais da cena 1 e a pessoa cujo corpo simplesmente desaparece são exemplos do que as autoras

\footnotetext{
${ }^{20}$ Farias (2007) argumenta que, no período recente, a construção social das favelas e seus moradores demarca um tratamento especial no que tange às políticas públicas e às formas de exercício de poder. Inspirada na ideia de "vida nua", que ela toma de empréstimo de Agamben, e na antropologia das margens do Estado para pensar as práticas cotidianas enraizadas no exercício do poder, a autora afirma que nas favelas se articulam micro-poderes e biopoder, transformando os seus moradores em uma população matável, definição que permite a qualquer momento colocar em risco o direito à vida deste grupo, mais ou menos como em qualquer momento a remoção pode se atualizar, já que está sempre "em potência".
} 
apontam como o Estado de exceção arraigado nas práticas cotidianas; ambos estão acima, fora ou são anteriores lei.

As cenas descritas nos apontam para continuidades e descontinuidades (ou reconfigurações) da ação policial nas áreas pacificadas, as quais só podem ser descritas e analisadas sob a lógica a partir da qual se entenda as favelas como margens produzidas pelo Estado, isto é, espaços em que sua ação abre brechas para reinvenções na forma de governar e manter a ordem.

Como dissemos na introdução, e ficou claro nas eleições de 2014, a "pacificação" veio pra ficar, ou, "venceu"; entretanto, as reconfigurações e a dimensão repressiva do controle social nas atividades cotidianas, trazidas pelas UPPs, mais a continuidade da criminalização desses espaços e da produção de corpos cujas mortes ou desaparecimentos são amplamente desejáveis, a despeito da presença policial, no permite perguntar: e os "pacificados"?

\section{Considerações finais.}

O artigo teve o objetivo de apresentar um olhar mais apurado sobre a atuação das agências estatais nas favelas da cidade do Rio de Janeiro, entendendo que uma agenda de estudos interessante emerge quando nos debruçamos sobre algumas práticas de ordenamento urbano e gestão de populações. Tomou-se, aqui, como estratégia analítica a ideia de que as favelas são margens produzidas pelo Estado tal como proposto por Das e Poole (2004), não a partir de uma delimitação geográfica previamente estabelecida ou um lugar periférico, onde o estado atua de modo enfraquecido, mas pelo seu oposto, entendo esse espaço como prenhe de estado, de suas regulações, agências e atores. 
Desde essa perspectiva, é possível encontrar os parâmetros descritivos para se etnografar o estado (Telles, 2010).

Neste trabalho, optou-se por descrever práticas policiais, mas outros objetos se colocam, como no citado trabalho de Gonçalves (2013) em que ele aponta a "tolerância" do poder público para com a informalidade fundiária e urbanística das áreas entendidas como de favelas como prerrogativa para negar a prestação de serviços e a implantação de equipamento públicos nesses territórios. Sob essa perspectiva, a construção das favelas como espaços distintivos permitem uma reconfiguração da atuação estatal nessas áreas, abrindo arenas para diversas negociações, conflitos e alianças locais, nas quais o aparato estatal é apenas um dos atores.

O desdobramento das cenas aqui apresentadas nos leva a caminhos em que a atuação policial aponta descontinuidades com suas funções ordinárias: ao se negar a cumprir seu serviço regimental (pois nas favelas outras regras para gestão de conflitos violentos vigorariam), quando se propõe a ser mediador político dos moradores com outras agências prestadoras de serviço e quando ela reproduz práticas sociais históricas de criminalização dos pobres e dos espaços de pobreza ao coagir uma reunião política pública com novos aparatos tecnológicos.

O experimento das UPPs tem se constituído numa nova forma de gestão da manutenção do ordenamento público carioca (Machado da Silva, 2012:121), legitimado principalmente pelas alardeadas estatísticas que comprovam a redução da letalidade nas favelas e expressam os esforços oficiais para evidenciar que a pacificação "venceu", tal como polemizado aqui. Contudo, esta forma de gestão que as UPPs inauguram convive com um debate público desequilibrado, onde a forte aprovação pública do policiamento repressivo contrasta com a impossibilidade de manifestação dos moradores de favela, seja pela incerteza da continuidade do programa após os jogos olímpicos, seja pela 
comprovada continuidade da atuação do trafico varejista de drogas nos espaços militarizados (idem:123), compartilhando poderes e práticas distintas, como foi exposto numa das cenas deste artigo.

Os moradores dessas favelas (aqueles que, no discurso oficial em torno das UPPs, necessitam de ser "pacificados") são aqueles que cotidianamente precisam transitar entre diferentes lógicas e jogos de poder. Obrigados a conviver com os portadores da ordem social que Machado da Silva chama de "sociabilidade violenta", e identificados, na gramática da violência urbana, como parte do grupo que não é portador de direitos (pois representados hegemonicamente como "bandidos em potencial"21), os moradores de favela compreenderiam o que Farias (2007) chama de "população matável". Em lugares onde os direitos podem ser violados através de práticas e documentações erigidas pelo próprio Estado, torna-se fácil compreender como a produção das margens serve à própria manutenção de um determinado estado de coisas - no caso, a visão positiva do processo de "pacificação" pela opinião pública e a manutenção de um grupo específico de sujeitos passível de sofrer com toda sorte de ilegalismos.

As considerações feitas aqui têm o intuito de dar continuidade aos debates já constituídos sobre as diversas configurações do "problema da favela" ao longo dos últimos anos. Aqui, foi proposto um exercício de entender as favelas como margens produzidas pelo Estado, deslocando a análise (da relação entre Estado e favela) do nível

21 Referimo-nos, aqui, ao fato de que, na linguagem da violência urbana, a população favelada é diretamente associada aos traficantes varejistas de drogas ilícitas, entendidos como os agentes de uma ordem social que tem na força bruta seu único elemento de coordenação das ações. Assim: "toda a população moradora de favelas passou a ser visto como composta por bandidos ou quase bandidos, em razão da contiguidade territorial inescapável com a minoria que integra os bandos armados. Emparedada, vive uma vida sob cerco. De um lado, pela violência criminal e policial que desestabiliza a sociabilidade em seus territórios de moradia (e de trabalho, para muitos) e dificulta o prosseguimento regular das interações nas diferentes localidades (...) De outro lado, o medo e a desconfiança generalizados das camadas mais abastadas da cidade obrigam os moradores de favelas a um esforço prévio de 'limpeza simbólica' - isto é, a necessidade de demonstrar ser 'pessoa (ou grupo) de bem', a fim de ganhar a confiança do Outro -, poucas vezes bem-sucedido, antes mesmo que possam apresentar no espaço público suas demandas como interlocutores legítimos" (idem:14-15).

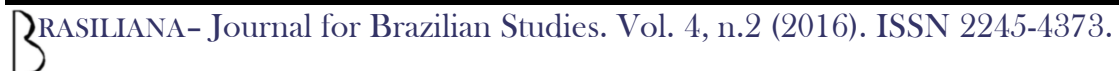


das formulações das políticas públicas para esses territórios para o registro da forma como essas soluções se realizam efetivamente, na forma ordinária e cotidiana da atuação de uma agência governamental, a polícia. É na territorialização do Estado que as margens são criadas e, estando em constante movimento, cabe a indicação de que as nuances e as especificidades que as constituem sejam objetos de novas investigações.

\section{Referências Bibliográficas}

Athayde, Celso; Meirelles, Renato. Um país chamado favela: a maior pesquisa já feita sobre a favela brasileira. São Paulo: Editora Gente, 2014.

Azevedo, Lena; Faulhaber, Lucas. SMH 2016: remoções no Rio de Janeiro Olímpico. Rio de Janeiro: Mórula, 2015.

Barbosa, Antonio Rafael; Renoldi, Brígida. Introdução. In: A.R. Barbosa, B. Renoldi e M. Veríssimo (orgs.). (I)legal: etnografias em um fronteira difusa. Niterói: Editora da UFF, 2013.

Brum, Mario Sergio. Favelas e remocionismo ontem e hoje: da Ditadura de 1964 aos Grandes Eventos. O Social em Questão - Ano XVI - no 29 - 2013; pg 179-208.

Cano, Ignácio et alii. 'Os donos do morro': uma avaliação exploratória do impacto das Unidades de Polícia Pacificadora (UPPs) no Rio de Janeiro. Fórum Brasileiro de Segurança Pública em cooperação com o Laboratório de Análise da Violência - (LAV-UERJ). 2012.

Comitê Popular da Copa e Olimpíadas do Rio de Janeiro. Dossiê: Megaeventos e Violações de Direitos Humanos no Rio de Janeiro. 2014.

Chaterjee, Partha. Colonialismo, Modernidade e Politica. Salvador - Bahia, EDUFBA: 2004.

Das, Venna. The Signature of State: The Paradox of Illegibility. In.: Das, Veena; poole, Deborah (Org). The Anthropology in the margins of the State. Santa Fe, Novo México: School of American Research Press, 2004, pp. 225-251. 
. Poole, Deborah. State and Its Margins: Comparative Ethnografies. In.: Das, Veena; Poole, Deborah (Org). The Anthropology in the margins of the State. Santa Fe, Novo México: School of American Research Press, 2004, pp. 3-34.

Elias, Norbert. 1994. O Processo Civilizador - Volume 1: Uma História dos Costumes. Rio de Janeiro: Jorge Zahar Ed. 2v. 1994.

. O Processo Civilizador - Volume 2: Formação do Estado e Civilização. Rio de Janeiro: Jorge Zahar Ed. 2v. 1994a.

Farias, Juliana. Quando a exceção vira regra: os favelados como população "matável" e sua luta por sobrevivência. TEORIA e SOCIEDADE nº 15.2 - julho-dezembro de 2007 p. 138-171.

Gonçalves, Rafael Soares. Favelas do Rio de Janeiro: História e direito. Rio de Janeiro, Pallas, Ed. PUC-Rio, 2013.

. Magalhães, Alex Ferreira; Simões, Soraya Silveira. Apresentação. Grandes eventos, múltiplos impactos, grandes mobilizações. O Social em Questão - Ano XVI - no 29 - 2013b.

La Barre, Jorge de. Choque de futuro: o Rio dos megaeventos. O Social em Questão - Ano XVI - no 29 - 2013pg 43-68.

La Rocque, Eduarda. A construção de um novo tecido social. Trabalho apresentado no Fórum Nacional do INAE. 2013. Disponível em: http://www.rio.rj.gov.br/documents/91329/9ca3b31c-90a3-4aec-b59a-5e92c6e8833a. 2013.

; Boavista, José Marcelo Souza. Inclusão social e o papel do mercado financeiro. Revista RI. 2012.

Leite, Márcia Pereira. Entre a 'guerra' e a 'paz': Unidades de Polícia Pacificadora e gestão dos territórios de favela no Rio de Janeiro. Dilemas: Revista de Estudos de Conflito e Controle Social - Vol. 7 - no 4 - OUT/NOV/DEZ 2014 - pp. 625-642.

Lima, Antonio Carlos de Souza. Um grande cerco de paz: poder tutelar, indianidade e formação do Estado no Brasil. Petrópolis, RJ: Vozes, 1995.

3RASILIANA- Journal for Brazilian Studies. Vol. 4, n.2 (2016). ISSN 2245-4373. 
Machado da Silva, Luiz Antonio. Violência urbana: representação de uma ordem social. In: E.P. Nascimento e I.A.F. Barreira (orgs.). Brasil urbano: cenários da ordem e da desordem. Rio de Janeiro: Notrya, 1993.

- Violência e sociabilidade: tendências da atual conjuntura urbana brasileira. In: L. C. Ribeiro e O. Santos Jr (orgs), Globalização, fragmentação e reforma urbana. O futuro das cidades brasileiras na crise. Rio de Janeiro, Civilização Brasileira, 1994.

. A Continuidade do Problema da Favela. In: Lucia Lippi de Oliveira. (Org.). Cidade: História e Dasafios. Rio de Janeiro: FGV, 2002, v. , p. 220-237.

. Introdução, in: Machado da Silva, Luiz Antônio (org). Vida sob cerco: violência e rotina nas favelas do Rio de Janeiro. Rio de Janeiro, Nova Fronteira, 2008a.

- Apontamentos metodológicos, in: Machado da Silva, Luiz Antônio (org). Vida sob cerco: violência e rotina nas favelas do Rio de Janeiro. Rio de Janeiro, Nova Fronteira, 2008b.

- Violência urbana, sociabilidade violenta e agenda pública, in: Machado da Silva, Luiz Antônio (org). Vida sob cerco: violência e rotina nas favelas do Rio de Janeiro. Rio de Janeiro, Nova Fronteira, 2008c.

- Afinal, qual é a das UPPs? Disponível em: http://www.observatoriodasmetropoles.ufrj.br/artigo_machado_UPPs.pdf; 2010.

- As UPPs, a linguagem da violência urbana e a sociabilidade no Rio de Janeiro. In: Angela Moulin S. Penalva Santos; Glaucio José Marafon; Maria Josefina Gabriel Sant'Anna. (Org.). Rio de Janeiro - um território em mutação. 1ed. Rio de Janeiro: Gramma/Faperj, 2012, v. 1, p. 115-131.

Magalhães, Alexandre Almeida de. Transformações no "problema favela" e a reatualização das remoções no Rio de Janeiro. Tese apresentada no Programa de Pós-Graduação em Sociologia pelo IESP-UERJ, 2013.

Matiolli, Thiago Oliveira Lima Matiolli. Notas sobre o surgimento de um bairro. In.: Rodrigues, Rute Imanishi (org.) Vida Social e Política nas Favelas: pesquisas de campo no Complexo do Alemão, RJ. IPEA, CEPEDOCA, Rio de Janeiro, 2016 (No prelo). 
Misse, Michel. Crime e violência no Brasil Contemporâneo: estudos de sociologia do crime e da violência urbana. Rio de Janeiro, Lumen Juris, 2006.

. Crime, Sujeito e Sujeição Criminal: aspectos de uma contribuição analítica sobre a categoria "bandido". Lua Nova, São Paulo, n. 79, 2010, pp. 15-38.

Pacheco de Oliveira, João. Pacificação e tutela militar na gestão de populações e territórios. MANA 20(1): 125-161, 2014.

Pastuki, Marília; Velloso, João Paulo dos Reis. (orgs). Favela como oportunidade: plano de desenvolvimento de favelas para sua inclusão social e econômica. Rio de Janeiro: INAE, 2012.

Rodrigues, André e Siqueira, Raíza. As unidades de polícia pacificadora e a segurança pública no Rio de Janeiro, in: Cadernos do ISER: Unidades de Polícia Pacificadora: debates e reflexões. Rio de Janeiro: ISER, n.67, ano 31, 2012.

Telles, Vera da Silva. A cidade nas fronteiras do legal e ilegal. Belo Horizonte, MG. Argvmentvm, 2010.

Wermelinger, Claudia Serra. Formação do Estado e pacificação da vida: a abordagem da violência contemporânea a partir da obra de Norbert Elias. Teoria \& Sociedade $n^{\mathbf{0}} 17.1$ janeiro-junho de 2009 p.218-255.

Wouters, Cas. (1999), "Changing Patterns of Social Controls and Self-Controls: On the Rise of Crimes since the 1950s and the Sociogenesis of a "ThirdNature'". British Journal of Criminology, vol. 39, no 3, pp. 416-432.

Zaluar, Alba; Alvito, Marcos. Introdução. In: Zaluar, Alba e Alvito, Marcos (orgs.). Um século de favela. Rio de Janeiro: Editora FGV, 1998. 